\title{
Getting to zero: micro-foci of malaria in the Solomon Islands requires stratified control
}

\author{
Tanya L. Russell ${ }^{1 *}\left(\mathbb{D}\right.$, Lynn Grignard ${ }^{2}$, Alan Apairamo ${ }^{3}$, Nathan Kama ${ }^{3}$, Albino Bobogare ${ }^{3}$, Chris Drakeley ${ }^{2}$ and
} Thomas R. Burkot ${ }^{1}$

\begin{abstract}
Background: The Solomon Islands has made significant progress in the control of malaria through vector control, access and use of improved diagnostics and therapeutic drugs. As transmission is reduced there is a need to understand variations in transmission risk at the provincial and village levels to stratify control methods.

Methods: A cross-sectional survey of malaria in humans was conducted in the Solomon Islands during April 2018. Nineteen villages across 4 provinces were included. The presence of Plasmodium species parasites in blood samples was detected using PCR.

Results: Blood samples were analysed from 1,914 participants. The prevalence of DNA of Plasmodium falciparum was $1.2 \%(n=23)$ and for Plasmodium vivax was $1.5 \%(n=28) .22 \%(n=5 / 23)$ of $P$. falciparum DNA positive participants were febrile and $17 \%$ of $P$. vivax DNA positive participants $(n=5 / 28)$. The prevalence of both $P$. falciparum and $P$. vivax was extremely spatially heterogeneous. For $P$. falciparum, in particular, only 2 small foci of transmission were identified among 19 villages. Plasmodium falciparum infections were uniformly distributed across age groups. Insecticidetreated bed net use the night prior to the survey was reported by $63 \%$ of participants and significantly differed by province.

Conclusions: Malaria transmission across the Solomon Islands has become increasingly fragmented, affecting fewer villages and provinces. The majority of infections were afebrile suggesting the need for strong active case detection with radical cure with primaquine for P. vivax. Village-level stratification of targeted interventions based on passive and active case detection data could support the progress towards a more cost-effective and successful elimination programme.
\end{abstract}

Keywords: Plasmodium falciparum, Plasmodium vivax, Solomon Islands, Malaria elimination, Heterogeneous transmission

\section{Background}

Since the beginning of the millennium, substantial progress was made to reduce the global incidence of human malaria, with 12 new countries being certified as

\footnotetext{
*Correspondence: tanya.russell@jcu.edu.au

${ }^{1}$ Australian Institute of Tropical Health and Medicine, James Cook University, Cairns, Australia

Full list of author information is available at the end of the article
}

malaria-free since 2007 [1, 2]; however, these gains have plateaued over recent years. Countries making significant progress to reduce transmission are committing to malaria elimination by 2030 [3]. As malaria transmission reduces, malaria cases become more spatially heterogeneous $[4,5]$. In response, national malaria programmes are encouraged to use local evidence to design and implement a mix of interventions by transmission stratum,

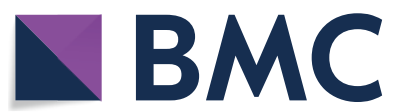

(c) The Author(s) 2021. This article is licensed under a Creative Commons Attribution 4.0 International License, which permits use, sharing, adaptation, distribution and reproduction in any medium or format, as long as you give appropriate credit to the original author(s) and the source, provide a link to the Creative Commons licence, and indicate if changes were made. The images or other third party material in this article are included in the article's Creative Commons licence, unless indicated otherwise in a credit line to the material. If material is not included in the article's Creative Commons licence and your intended use is not permitted by statutory regulation or exceeds the permitted use, you will need to obtain permission directly from the copyright holder. To view a copy of this licence, visit http://creativeco mmons.org/licenses/by/4.0/. The Creative Commons Public Domain Dedication waiver (http://creativecommons.org/publicdomain/ zero/1.0/) applies to the data made available in this article, unless otherwise stated in a credit line to the data. 
rather than utilizing a one-size-fits-all approach [6]. In countries controlling malaria, interventions can be targeted to entire villages with higher malaria incidence until only individual episodes of malaria remain and programmes have the capacity to investigate and respond focally [3].

The Solomon Islands has made significant progress to control malaria through vector control, access and use of improved diagnostics and therapeutic drugs. Vector control has been the principal preventative intervention to reduce malaria transmission over the past two decades with long-lasting insecticidal nets (LLINs) and IRS, both globally and in the Solomon Islands. These strategies have seen Plasmodium falciparum replaced by Plasmodium vivax as the dominant malaria parasite in the Solomon Islands [7].

Here the annual parasite incidence (API) was reduced from over 200 per thousand in 2003 to just below 30 per thousand in 2014. However, since 2015, the API has increased reaching 107 per thousand in 2019. This resurgence has delayed the goal of malaria elimination with the priority of the 2021-2025 Strategic Plan now seeking to reach zero cases by 2034 [8]. In 2019, four provinces contributed to approximately $86 \%$ of the malaria burden in the country: Central Islands (10.5\%), Guadalcanal (27.1\%), Honiara (15.2\%), and Malaita (33.1\%) [8]. The malaria caseloads, in the other six provinces (Choiseul $0.7 \%$, Isabel $0.5 \%$, Makira $4.2 \%$, Rennell-Bellona $0 \%$, Temotu $2.5 \%$, and Western $6.0 \%$ ) were responsible for only $14 \%$ of the national malaria burden [8]. This heterogeneity argues for a stratified approach to malaria control. Here, a cross-sectional survey of malaria in humans was undertaken to understand the heterogeneity in malaria transmission risk at the provincial and village levels.

\section{Methods}

\section{Study site}

The cross-sectional study was conducted in the Solomon Islands $\left(-8.0^{\circ} \mathrm{S}, 157.0^{\circ} \mathrm{E}\right)$ in April 2018. The Solomon Islands is hot and wet with an annual rainfall of 2,005 mm (mean for 1999-2017 at Henderson Airport, Guadalcanal Island). Rain falls year round with a peak during January to March. The mean daily coastal temperature ranges between 24 and $30^{\circ} \mathrm{C}$ with a mean of $26^{\circ} \mathrm{C}$.

The four study sites-Honiara City Council as well as Guadalcanal, Isabel and Malaita Provinces-were selected in consultation with the Ministry of Health and Medical Services, Solomon Islands. Survey sites were selected to cover a range of transmission scenarios from low to high transmission, and to include areas with $P$. falciparum cases based on passive case detection at health facilities. Inclusion criteria required villages to have a minimum resident population of 200 , and to be accessible by sea or road. The sites encompassed 19 suburbs and villages (Fig. 1), hereforth termed villages.

\section{Field procedures}

All residents in selected villages, over the age of 5 years, were invited to participate in the study. The only exclusion criteria was the resident's unwillingness to participate in the study. Residents were equally encouraged to participate across age categories and genders. After enrolment, demographic information and data on possible risk and protective factors associated with mosquito-borne diseases of participants were collected. Data collected included: (1) name, age, gender, household number, (2) fever history, (3) malaria diagnosis and treatment history and (4) access/use of mosquito protection measures. The typanic temperature of participants was measured (Welch Allyn Braun ThermoScan Pro 6000) and any febrile individuals (temperatures $>38{ }^{\circ} \mathrm{C}$ ) were immediately referred to the nearest health facility.

Each participant provided $\mathrm{a} \leq 10 \mathrm{ml}$ blood sample by venepuncture using vacutainers, drawn by a nurse trained and employed by the Ministry of Health and Medical Services. Five $\mu$ of selected blood samples was immediately tested for malaria using the AccessBio CareStart rapid diagnostic test (RDT) (G0161) according to the manufacturer's instructions. Concurrently, $3 \times 50 \mu \mathrm{l}$ blood spots were placed onto cellulose chromatography papers $\left(2 \times 7 \mathrm{~cm}\right.$; Whatman ${ }^{\circledR}$ Grade $\left.3 \mathrm{MM}\right)$ and dried under ambient conditions. Dried blood spots were stored in individual snap-lock bags and sealed in an airtight container with silica gel.

Serum was separated by centrifugation at $1,500 \mathrm{~g}$ for $10 \mathrm{~min}$. Serum and clots were initially stored at $4{ }^{\circ} \mathrm{C}$, then frozen at $-20{ }^{\circ} \mathrm{C}$ within 4 days, until shipped internationally on dry ice and subsequently stored at $-80{ }^{\circ} \mathrm{C}$ until analysed. A unique code was assigned to each participant and their associated samples.

\section{PCR detection of Plasmodium spp. parasites}

Dried blood spot (DBS) samples were pooled (4 samples/ pool) for extraction using the Chelex/saponin method [adapted from 9]. For each sample, $2 \times 3 \mathrm{~mm}$ punches were used, being the equivalent of $2 \times 2 \mu \mathrm{l}$ of blood. Each sample was eluted to $150 \mu \mathrm{l}$, from which $5 \mu \mathrm{l}$ of template was used in both nPCR and qPCR. Extracted nucleic acid were amplified in a nested PCR targeting the pan Plasmodium $18 S$ gene [10,11]. Positive pools were de-pooled and each sample in the pool was individually extracted as above and further analyed by pan genus and species-specific nested PCR $[10,11]$. Where all de-pooled samples were negative in the nested PCR, blood clots were analysed by real-time PCR [12] targeting genus-sepcific $18 \mathrm{~S}$ 


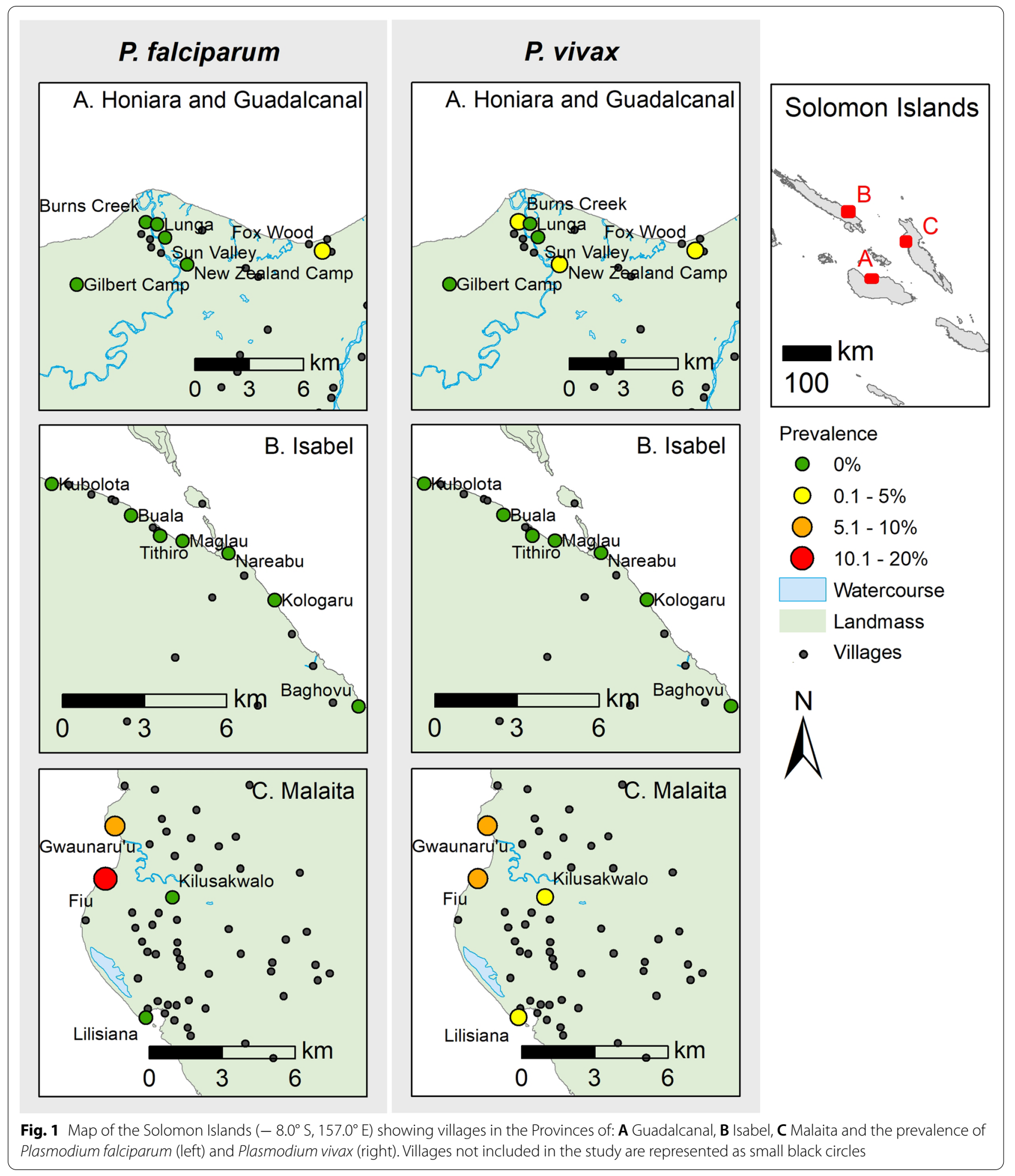

Plasmodium followed by a multiplex reaction targeting $P$. falciparum, P. vivax, Plasmodium malariae and Plasmodium ovale.

\section{Statistical analysis}

The relationship of province on use of insecticide-treated nets (ITNs), other vector control measures, domestic and international travel history and malaria positivity were 
compared using a chi-squared contingency table (chisq. test).

The relationship between malaria PCR positive explanatory variables was analysed using a generalized linear model (GLM; package MASS) with a binomial distribution, a binary dependent variable (i.e., negative or positive). Step-forward multi-model inference (MMI), based on ranking the value of the Akaike's Information Criterion (AIC), was used to select the explanatory variables that best described malaria PCR positivity. The relative strength of evidence for each model within the set of alternatives was assessed using Akaike weights (wAIC) where the wAIC for each model is interpreted as the probability for the most likely model, with support varying from 0 (no support) to 1 (total support) [13-15]. The most parsimonious model from the final set of nested models was compared with the likelihood ratio test and compared with the $X^{2}$ distribution $[16,17]$. The explanatory variables were village, gender, temperature, age, ITN use and malaria history. Analyses were performed using the R package (v3.5.1).

\section{Results}

\section{Study population}

A total of 1,977 individuals (215 from Honiara, 221 from Guadalcanal, 392 from Western Malaita, and 996 from Isabel) participated in the study. Participants had a median age of 30 years, with $62 \%$ being female (Table 1 ). The average tympanic temperature of participants during the survey was $37.1{ }^{\circ} \mathrm{C}$, and 34 people had a temperature exceeding $38^{\circ} \mathrm{C}$ at the time of the survey, with the maximum temperature recorded being $40.6^{\circ} \mathrm{C}$.

\section{Vector control}

Insecticide-treated bed net use (predominately longlasting insecticide treated nets (LLINs)) the night prior to the survey was reported by $63 \%$ of participants and

Table 1 Study population summary characteristics

\begin{tabular}{ll}
\hline Characteristic & Summary \\
\hline Survey dates & Apr 2018 \\
Number of participants & 1,977 \\
Number of samples analysed & 1,914 \\
Age-Range & $5-86$ years \\
Age-Median & 30 years \\
Percentage female & $62 \%(n=1,229)$ \\
P. falciparum prevalence & $0.9 \%(n=17 / 1914)$ \\
P. vivax prevalence & $1.1 \%(n=22 / 1914)$ \\
Mixed infection prevalence & $0.3 \%(n=6 / 1914)$ \\
Percentage P. vivax & $61 \%(n=28 / 46)$ \\
\hline
\end{tabular}

significantly differed by province $\left(\chi^{2}=141.49 \mathrm{df}=4\right.$, $\mathrm{p}<0.0001$; Fig. 2), ranging from $48 \%$ in Malaita Province to $75 \%$ in Isabel Province. The use of ITNs also varied by villages from $29 \%$ in Lilisiana, Malaita to $95 \%$ in Hovukoilo Village in Isabel (Additional file 1: Table S1). There was limited use of other mosquito protective measures; $10 \%$ of study participants used mosquito coils (usually a volatile pyrethroid) and $5 \%$ of survey participants' houses had window screens. Topical repellents were used by only $0.8 \%$ of survey participants. The use of other mosquito control measures was significantly related to the province $\left(\mathrm{x}^{2}=301.27 \mathrm{df}=4, \mathrm{p}<0.0001\right)$, with higher mosquito coil use in Honiara and Guadalcanal (39 and 29\%, respectively), and $16 \%$ of participant houses in Western Malaita having window-screens (Fig. 2).

\section{Plasmodium prevalence by PCR}

Blood samples from 1,914 participants were analysed by PCR for Plasmodium spp. DNA (henceforth, DNA malaria positive participants are referred to as malariapositive and used to determine malaria prevalences): 46 participants were malaria positive with 17 individuals positive for $P$. falciparum, 22 with $P$. vivax, 6 with both $P$. falciparum and $P$. vivax, and a single individual with $P$. ovale (Table 2). Of Plasmodium PCR positive individuals, seven were febrile (temperature $\geq 38^{\circ} \mathrm{C}$ ): 2 were positive for $P$. falciparum, 2 were positive for $P$. vivax and 3 were PCR positive with both $P$. falciparum and $P$. vivax;

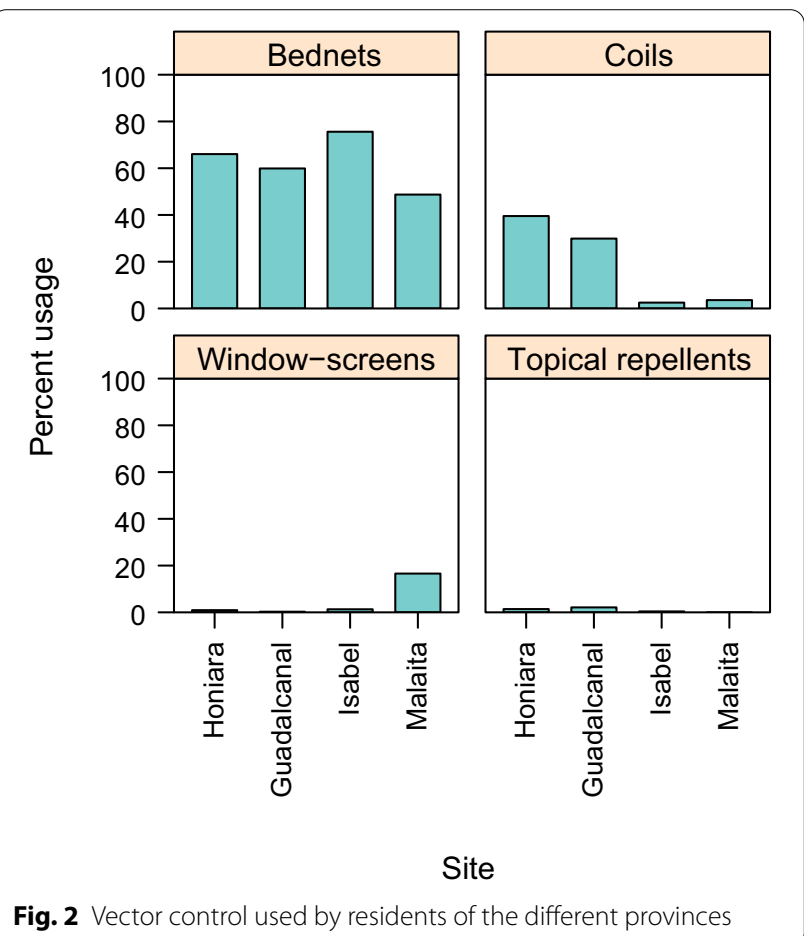


Table 2 The prevalence of Plasmodium DNA-positives across provinces in the Solomon Islands among residents of all ages above 5 years

\begin{tabular}{|c|c|c|c|c|c|c|c|c|}
\hline \multirow[b]{2}{*}{ Province } & \multirow[b]{2}{*}{ Participants } & \multicolumn{4}{|c|}{ Number positive } & \multicolumn{3}{|c|}{ Prevalence } \\
\hline & & Mixed $^{\mathrm{a}}$ & $\mathrm{Pf}$ & $\mathrm{Pv}$ & Po & $\mathrm{Pf}$ & $\mathrm{Pv}$ & Overall \\
\hline Honiara & 211 & 0 & 0 & 4 & 0 & $0.0 \%$ & $1.9 \%$ & $1.9 \%$ \\
\hline Guadalcanal & 369 & 1 & 0 & 3 & 0 & $0.3 \%$ & $1.1 \%$ & $1.1 \%$ \\
\hline Isabel & 946 & 0 & 0 & 0 & 0 & $0.0 \%$ & $0.0 \%$ & $0.0 \%$ \\
\hline Malaita & 388 & 5 & 17 & 15 & 1 & $5.7 \%$ & $5.2 \%$ & $9.8 \%$ \\
\hline Overall & 1,914 & 6 & 17 & 22 & 1 & $1.2 \%$ & $1.5 \%$ & $2.4 \%$ \\
\hline
\end{tabular}

${ }^{a}$ The mixed infections contained both $P$. falciparum and $P$. vivax

Table 3 The number and percentage of participants that were positive for either P. falciparum, or P. vivax summarized by the various explanatory variables

\begin{tabular}{|c|c|c|c|c|c|}
\hline \multirow[t]{2}{*}{ Parameter } & \multirow[t]{2}{*}{ Total } & \multicolumn{2}{|c|}{ P. falciparum } & \multicolumn{2}{|c|}{ P. vivax } \\
\hline & & $\mathbf{n}$ & $\%$ & $\mathrm{n}$ & $\%$ \\
\hline \multicolumn{6}{|l|}{ Gender } \\
\hline Female & 1197 & 14 & $1.2 \%$ & 14 & $1.2 \%$ \\
\hline Male & 717 & 9 & $1.3 \%$ & 14 & $1.9 \%$ \\
\hline \multicolumn{6}{|l|}{ Fever } \\
\hline Yes & 34 & 5 & $14.7 \%$ & 5 & $14.7 \%$ \\
\hline No & 1880 & 18 & $0.9 \%$ & 23 & $1.2 \%$ \\
\hline \multicolumn{6}{|c|}{ Domestic travel history } \\
\hline Yes & 79 & 0 & $0.0 \%$ & 2 & $2.5 \%$ \\
\hline No & 1835 & 23 & $1.3 \%$ & 26 & $1.4 \%$ \\
\hline \multicolumn{6}{|c|}{ International travel history } \\
\hline Yes & 49 & 0 & $0.0 \%$ & 1 & $2.0 \%$ \\
\hline No & 1865 & 23 & $1.2 \%$ & 27 & $1.4 \%$ \\
\hline \multicolumn{6}{|l|}{ Bed net use } \\
\hline Yes & 1275 & 11 & $0.9 \%$ & 6 & $0.5 \%$ \\
\hline No & 639 & 12 & $1.9 \%$ & 22 & $3.4 \%$ \\
\hline \multicolumn{6}{|c|}{ Malaria history } \\
\hline Yes & 884 & 14 & $1.6 \%$ & 15 & $1.7 \%$ \\
\hline No & 1016 & 9 & $0.9 \%$ & 13 & $1.3 \%$ \\
\hline \multicolumn{6}{|l|}{ Medicine use } \\
\hline Yes & 33 & 0 & $0.0 \%$ & 1 & $3.0 \%$ \\
\hline No & 1881 & 23 & $1.2 \%$ & 27 & $1.4 \%$ \\
\hline
\end{tabular}

Table 3). Thus, the percentage of febrile or symptomatic participants for $P$. falciparum was $22 \%(\mathrm{n}=5 / 23)$ and for P. vivax was $17 \%(\mathrm{n}=5 / 28)$.

For P. falciparum, the base GLM model was most substantially improved by adding village $(100 \%$ wAIC support). Sequentially the model was improved by adding temperature (93\% wAIC support, Fig. 3). These explanatory variables of village and temperature were significant (log-likelihood ratio test) and were included in the most parsimonious model (Table 4). None of the other

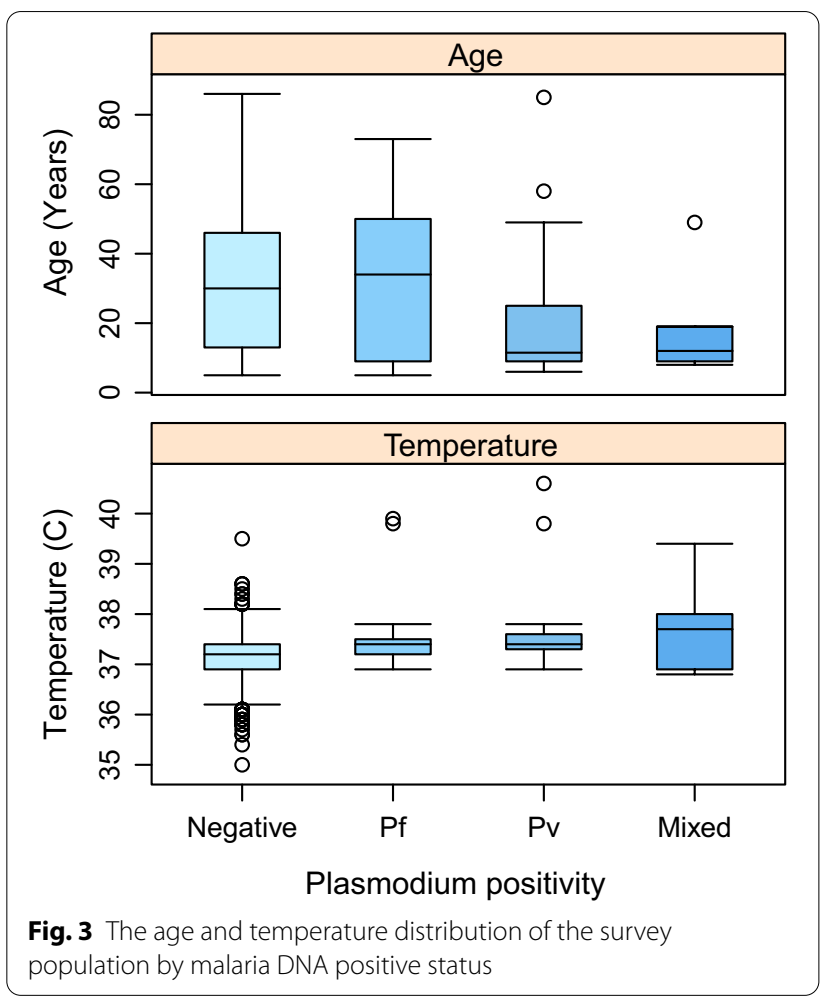

remaining candidate factors were able to further improve model fit. Of note is that although the prevalence of $P$. falciparum was reduced almost by half from 1.9 to $0.9 \%$ by using an ITN (Table 3), this factor did not explain sufficient variation to be included in the final model.

Much of the variation in P. falciparum prevalence was explained by village, and this species was extremely heterogeneous across the provinces, with only 2 small foci of transmission identified among 19 villages surveyed (Fig. 1). Plasmodium falciparum DNA positive samples were extremely localized, there was 1 mixed positive sample from Guadalcanal $(n=119)$ and the remaining 22 positive participants were from only 2 villages in Malaita. 
Table 4 Final set of nested models evaluated to determine which best predicted the prevalence of Plasmodium DNA-positives

\begin{tabular}{|c|c|c|c|c|c|c|}
\hline Model & df & AIC & $\Delta \mathrm{AIC}$ & wAIC & $x^{2}$ & $p$ value \\
\hline \multicolumn{7}{|l|}{ Plasmodium falciparum } \\
\hline Village & 19 & 183.91 & 7.31 & 0.0147 & & \\
\hline Village + Temperature & 20 & 176.59 & 0.00 & 0.5694 & 9.31 & $0.0022^{*}$ \\
\hline $\begin{array}{l}\text { Village + Temperature + } \\
\text { Bed net use }\end{array}$ & 21 & 177.22 & 0.63 & 0.4157 & 1.37 & 0.241 \\
\hline \multicolumn{7}{|l|}{ Plasmodium vivax } \\
\hline Village & 19 & 253.64 & 23.87 & $<0.0001$ & & \\
\hline Village + Temperature & 20 & 241.25 & 11.48 & 0.0023 & 14.39 & $0.0001^{*}$ \\
\hline $\begin{array}{l}\text { Village + Temperature + } \\
\text { Bed net use }\end{array}$ & 21 & 231.74 & 1.97 & 0.2714 & 11.51 & $0.0007^{*}$ \\
\hline $\begin{array}{l}\text { Village }+ \text { Temperature }+ \\
\text { Bed net use }+ \text { Gender }\end{array}$ & 22 & 229.77 & 0.00 & 0.7261 & 3.98 & $0.0463^{*}$ \\
\hline
\end{tabular}

Model comparison was made on the basis $\triangle \mathrm{AIC}$, wAIC and goodness-of-fit using maximum likelihood estimation. The full list of explanatory variables included village, gender, temperature, age, bed net use and malaria history

Overall, $69 \%$ of the P. falciparum positives were from a single village, where the prevalence was $15.5 \%$ (Fig. 1). When compared at the provincial level, $P$. falciparum prevalence was highest in Malaita (Table 2).

For $P$. vivax, the base GLM model was most substantially improved by adding village ( $99 \%$ wAIC support). Sequentially the model was improved by adding temperature (87\% wAIC support, Fig. 3), bed net use (94\% wAIC support) and gender (51\% wAIC support). These explanatory variables of village, temperature, bed net use and gender were significant (log-likelihood ratio test), and were included in the most parsimonious model (Table 4). Adding age or malaria history was unable to further improve the model fit. While age was not included in the most parsimonious $P$. vivax model, a univariate GLM did pick up an influence of age on infection $\left(\chi^{2}=9.63, \mathrm{df}=1\right.$, $\mathrm{p}=0.0019$; Fig. 3 ). For gender, males were more likely to be positive for $P$. vivax (Table 3 ).

The $P$. vivax positive samples were heterogeneous across the villages, but they were not as extremely localized as the P. falciparum infections. Plasmodium vivax DNA was detected in participants from Guadalcanal $(\mathrm{n}=4)$, Honiara $(\mathrm{n}=4)$ and Malaita $(\mathrm{n}=20)$, across 7 villages. Overall $63 \%$ of the $P$. vivax positive individuals were found in 2 villages, where the prevalence was 8.0 and $9.7 \%$ (Fig. 1). Plasmodium spp. DNA was not detected from Isabel province participants.

\section{Discussion}

Historically in the Solomon Islands, P. falciparum was the dominant species with a higher prevalence in younger age groups $[18,19]$, but as transmission declined, the proportion of $P$. vivax cases increased and the prevalence of submicroscopic malaria infections was high [20,21], with malaria transmission becoming increasingly fragmented, affecting fewer villages and provinces $[7,20]$. Such heterogeneity in low malaria transmission settings was previously documented [22-25]. In the current study, most infected individuals were afebrile with the prevalence of P. falciparum uniformly distributed across age groups. The epidemiology of low malaria transmission observed here is not dissimilar to that encountered at the early 1970 s during the DDT-based Malaria Eradication Programme when prevalence dropped to $1.4 \%$ and $P$. vivax dominated [18]. Similar shifts in malaria epidemiology were also observed in Temotu and Isabel Provinces in the early $2010 \mathrm{~s}$ during elimination efforts in these two provinces [26, 27]. In the current study, statistical hotspots were not defined by geospatial statistics due to the difficulty to show statistical significance at such very low transmission intensities where only isolated foci remain [5].

Malaria transmission intensity is a function of both receptivity of the environment to support anopheline vector populations and the presence of malaria parasites in an area or the risk of introduction of malaria parasites [28] with most variability in local exposure to malaria due to differences in mosquito populations densities [29]. Previous work in the Solomon Islands argued that the biting rate of the dominant malaria vector, Anopheles farauti, is a better predictor of malaria receptivity than the sporozoite rate or entomological inoculation rate [30]. Considering the fundamental role of mosquito densities and survivorship on malaria transmission, vector control has been directly responsible for large reductions in malaria transmission, not only in the Solomon Islands [31-34], but globally [35]. In the Solomon Islands, household-based LLIN distributions have been continuously implemented since the early $2000 \mathrm{~s}$, with annual indoor residual spraying (IRS) in selected high burden areas 
until 2015. Here, the impact of LLIN use on the prevalence of $P$. falciparum was not detected, and this is likely a consequence of the low number of infections that were detected and the difficulty associated with detecting statistical significance at low transmission. LLIN use did significantly reduce $P$. vivax transmission with $94 \%$ wAIC support.

While malaria transmission has been reduced, it is important to highlight the fragility of these reductions and the ability of malaria transmission to quickly rebound. In the Solomon Islands, malaria incidence rebounded from 20/1,000 people in 1976 to 450/1,000 in 1992 after the Malaria Eradication Programme ended [33]. A recent systematic review across the years 19302000 identified 75 malaria resurgences across the globe, with $91 \%$ of resurgences resulting from delays in implementing malaria vector control strategies [36]. Hence, the World Health Organization (WHO) recommends that malaria control efforts, including vector control, must be maintained in receptive areas even after transmission has been eliminated. In the Solomon Islands, malaria transmission across the country has increased during the short time since this survey was completed. The reasons are multi-faceted and may include delays in vector control during decentralisation of the malaria control programme, decreased bioefficacy of LLINs [37], a shortage of LLINs per household, withdrawal of IRS and minimal use of primaquine to treat $P$. vivax hypnozoites [8].

The current WHO recommendations for elimination and post-elimination settings calls for stratified targeting of control efforts by transmission intensity zones [3, 38]. In response, the Solomon Islands Strategic Plan for Malaria Control and Elimination, 2021-2025 identified 24 high malaria burden health zones by passive case detection in the provinces of Central Islands, Guadalcanal, Honiara, Makira, Malaita, Temotu and Western. This study confirmed the locations of high malaria burden health zones in three of these provinces, defining the residual malaria foci as small in size (e.g., individual villages), and provides evidence supporting the implementation of the strategic plan to target these foci effectively.

The strategic plan outlines the strategies for vector control, case management and surveillance and response. For vector control, the aim is to achieve universal coverage with LLINs, and to use IRS to rapidly reduce incidence in high transmission and outbreak areas. Previous work demonstrated that the risk of being bitten by $A n$. farauti, the dominant malaria vector, occurs early in the evening and pre-dominantly in the peri-domestic areas of house verandas and kitchens [39]. Hence, targeted IRS in these high risk structures could enhance malaria control in residual malaria foci [40]. For case management, and in particular primaquine use, the lack of G6PD testing has been a barrier and the aim is to roll out point-of-care G6PD testing to improve usage of primaquine. For surveillance and response, the strategic plan outlines the steps for creating an elimination-ready case-based surveillance system for use in Isabel Province using reactive case detection (RACD) based on the 2-4-7 model. Cases will be reported within two days, investigated within four days and appropriate remedial measure taken within a week. Such stratified malaria control will require improved capacity [41] and data management to rapidly detect and report infection foci as well as to respond with targeted interventions against the vector and parasite [42].

\section{Conclusions}

Pockets of malaria were detected in highly localized foci in the Solomon Islands. This highlights the need for stratified malaria control with increased vector control in high transmission areas and case-based surveillance using RACD in low transmission areas with anti-malarial treatment including radical cure for $P$. vivax. Village-level stratification of targeted interventions could support the progress towards a cost-effective and successful elimination programme.

\section{Abbreviations}

ACT: Artemisinin-based combination therapy; AIC: Akaike's Information Criterion; API: Annual parasite incidence; G6PD: Glucose-6-phosphate dehydrogenase; GLM: Generalized linear model; IRS: Indoor residual spraying; ITN Insecticide treated net; LLIN: Long-lasting insecticidal net; MDA: Mass drug administration; MMI: Multi-model inference; RACD: Reactive case detection; RDT: Rapid diagnostic test; WHO: World Health Organization.

\section{Supplementary Information}

The online version contains supplementary material available at https://doi. org/10.1186/s12936-021-03779-y.

Additional file 1: Table S1. The number and percentage of participants that were positive for either P. falciparum or P. vivax, summarized by the various explanatory variables. Figure $\mathbf{S 1}$. Age trends of Plasmodium species infections detected by PCR.

\section{Acknowledgements}

The authors thank the survey participants. The support of the Ministry of Health and Medical Services is acknowledged, in particular from the Vector Borne Disease Programme: Francis Otto, George Fafale, John Susubi and Charles Togapura as well as the Provincial Medical Directors: Dr Joel Denty, Dr Sarah Habu, Dr Henry Kako and Dr Helen Marau.

\section{Authors' contributions}

Study design: TLR, AB, TRB; Data collection: TLR, AA, NK; Laboratory processing: LG; Data analysis and initial draft: TLR; Funding acquisition: TRB; Manuscript preparation: TLR, LG, CD, TRB. All authors read and approved the final manuscript. 


\section{Funding}

This study was funded by both the Australian Government through the Department of Foreign Affairs and Trade and the Global Good Fund I, LLC. The views expressed in this publication are those of the authors and are not necessarily the views of the Australian Government. The Australian Government neither endorses the views in this publication, nor vouches for the accuracy or completeness of the information contained within the publication. The Australian Government, its officers, employees and agents, accept no liability for any loss, damage or expense arising out of or in connection with, any reliance on any omissions or inaccuracies in the material contained in this publication.

\section{Availability of data and materials}

The datasets supporting the conclusions of this article are available in the JCU Tropical Data Hub repository, (https://doi.org/10.25903/4054-3m75).

\section{Declarations}

\section{Ethics approval and consent to participate}

Community meetings were held with all village residents prior to the survey, where the aims, the possible risks and potential benefits of the study were explained in Solomon Islands Pidgin to potential participants (residents 5 years of age or older). Participation was voluntary with written informed consent obtained prior to enrolment from each adult participant $>18$ years. For children between 13 and 18 years, signed consent was obtained from both the minor and a parent or guardian; for children between 5 and 13 years, signed consent was obtained from a parent or guardian. Ethical approvals for the study were obtained from the National Health Research \& Ethics Committee, Solomon Islands (HRE066/17), the James Cook University Human Research Ethics Committee, Australia (H7107) and the London School of Hygiene and Tropical Medicine Observational Research Ethics Committee $(16,167)$. The field sampling and subsequent analyses was performed in accordance with relevant guidelines and regulations of these research boards, and as stipulated in the approvals.

\section{Consent for publication}

Not applicable.

\section{Competing interests}

The authors declare that they have no competing interests.

\section{Author details}

${ }^{1}$ Australian Institute of Tropical Health and Medicine, James Cook University, Cairns, Australia. ${ }^{2}$ Department of Infection Biology, London School of Hygiene \& Tropical Medicine, London, UK. ${ }^{3}$ National Vector Borne Disease Control Programme, Ministry of Health and Medical Services, Honiara, Solomon Islands.

Received: 31 March 2021 Accepted: 22 May 2021

Published online: 05 June 2021

\section{References}

1. Li XH, Kondrashin A, Greenwood B, Lindblade K, Loku Galappaththy G, Alonso P. A historical review of WHO certification of malaria elimination. Trends Parasitol. 2019;35:163-71.

2. Countries and territories certified malaria-free by the World Health Organization [https://www.who.int/malaria/areas/elimination/malariafree-countries/en/]

3. WHO. A framework for malaria elimination. Geneva: World Health Organization; 2017.

4. Bousema T, Griffin JT, Sauerwein RW, Smith DL, Churcher TS, Takken W, et al. Hitting hotspots: Spatial targeting of malaria for control and elimination. PLOS MED. 2012;9:e1001165.

5. Mogeni P, Omedo I, Nyundo C, Kamau A, Noor A, Bejon P, et al. Effect of transmission intensity on hotspots and micro-epidemiology of malaria in sub-Saharan Africa. BMC Med. 2017;15:121.

6. WHO. Technical brief for countries preparing malaria funding requests for the Global Fund (2020-2022). Geneva: World Health Organization; 2020.

7. Waltmann A, Koepfli C, Tessier N, Karl S, Fola A, Darcy AW, et al. Increasingly inbred and fragmented populations of Plasmodium vivax associated with the eastward decline in malaria transmission across the Southwest Pacific. PLoS Negl Trop Dis. 2018;12:e0006146.

8. National Vectorborne Disease Control Programme. Solomon Islands Strategic Plan for Malaira Control and Elimination 2021-2025. Honiara: Ministry of Health and Medical Services; 2020.

9. Plowe CV, Djimde A, Bouare M, Doumbo O, Wellems TE. Pyrimethamine and proguanil resistance-conferring mutations in Plasmodium falciparum dihydrofolate reductase: polymerase chain reaction methods for surveillance in Africa. Am J Trop Med Hyg. 1995;52:565-8.

10. Snounou G, Viriyakosol S, XinPing Z, Jarra W, Pinheiro L, doRosario VE, et al. High sensitivity of detection of human malaria parasites by the use of nested polymerase chain reaction. Mol Biochem Parasitol. 1993.61:315-320.

11. Snounou G, Singh B. Nested PCR analysis of Plasmodium parasites. In. Doolan DL Ed. Malaria methods and protocols. Totowa, NJ: Humana Press; 2002: 189-203.

12. Shokoples SE, Ndao M, Kowalewska-Grochowska K, Yanow SK. Multiplexed real-time PCR assay for discrimination of Plasmodium species with improved sensitivity for mixed infections. J Clin Microbiol. 2009;47:975-80.

13. Burnham KP, Anderson DR. Multimodel inference: understanding AIC and BIC in model selection. Soc Methods Res. 2004;33:261-304.

14. Burnham KP, Anderson DR. Model selection and inference: a practical information-theoretic approach. 2nd ed. New York, USA: Springer-Verlag; 2002.

15. Link WA, Barker RJ. Model weights and the foundations of multimodel inference. Ecology. 2006;87:2626-35.

16. Pinheiro JC, Bates DH. Mixed-effects models in S and S-PLUS. New York: Springer; 2000.

17. Russell TL, Lwetoijera DW, Knols BGJ, Takken W, Killeen GF, Ferguson HM. Linking individual phenotype to density-dependent population growth: the influence of body size on the population dynamics of malaria vectors. Proc Biol Sci. 2011;278:3142-51.

18. Avery J. A review of the malaria eradication programme in the British Solomon Islands 1970-1972. P N G Med J. 1974;17:50-60.

19. Mizushima Y, Kato H, Ohmae H, Tanaka T, Bobogare A, Ishii A. Prevalence of malaria and its relationship to anemia, blood glucose levels, and serum somatomedin c (IGF-1) levels in the Solomon Islands. Acta Trop. 1994;58:207-20.

20. Waltmann A, Darcy AW, Harris I, Koepfli C, Lodo J, Vahi V, et al. High rates of asymptomatic, sub-microscopic Plasmodium vivax infection and disappearing Plasmodium falciparum malaria in an area of low transmission in Solomon Islands. PLoS Negl Trop Dis. 2015;9:e0003758.

21. Fink J, Jones PD. High prevalence of low-level parasitemia with Plasmodium vivax; in Makira-Ulawa Province presents a challenge for the diagnosis and eradication of malaria in Solomon Islands. Ochsner J. 2021;21:76.

22. Bejon P, Williams TN, Nyundo C, Hay SI, Benz D, Gething PW, et al. A microepidemiological analysis of febrile malaria in Coastal Kenya showing hotspots within hotspots. elife. 2014;3:e02130.

23. Björkman A, Cook J, Sturrock H, Msellem M, Ali A, Xu W, et al. Spatial distribution of falciparum malaria infections in Zanzibar: Implications for focal drug administration strategies targeting asymptomatic parasite carriers. Clin Infect Dis. 2017;64:1236-43.

24. Kattenberg JH, Gumal DL, Ome-Kaius M, Kiniboro B, Philip M, Jally S, et al. The epidemiology of Plasmodium falciparum and Plasmodium vivax in East Sepik Province, Papua New Guinea, pre- and post-implementation of national malaria control efforts. Malar J. 2020;19:198.

25. Sandfort M, Vantaux A, Kim S, Obadia T, Pepey A, Gardais S, et al. Forest malaria in Cambodia: the occupational and spatial clustering of Plasmodium vivax and Plasmodium falciparum infection risk in a cross-sectional survey in Mondulkiri province. Cambodia Malar J. 2020;19:413.

26. Harris I, Sharrock W, Bain L, Gray K-A, Bobogare A, Boaz L, et al. A large proportion of asymptomatic Plasmodium infections with low and submicroscopic parasite densities in the low transmission setting of Temotu Province, Solomon Islands: challenges for malaria diagnostics in an elimination setting. Malar J. 2010;9:254.

27. The Ministries of Health of Vanuatu and Solomon Islands, The Pacific Malaria Initiative Survey Group, Shanks D. Malaria on isolatedMelanesian islands prior to the initiation of malaria elimination activities. Malar J. 2010;9:218 
28. Wu SL, Sánchez CHM, Henry JM, Citron DT, Zhang Q, Compton K, et al. Vector bionomics and vectorial capacity as emergent properties of mosquito behaviors and ecology. PLoS Comput Biol. 2020;16:e1007446.

29. Smith DL, Musiime AK, Maxwell K, Lindsay SW, Kiware S. A new test of a theory about old mosquitoes. Trends Parasitol. 2021;37:185-94.

30. Burkot TR, Bugoro H, Apairamo A, Cooper RD, Echeverry DF, Odabasi D, et al. Spatial-temporal heterogeneity in malaria receptivity is best estimated by vector biting rates in areas nearing elimination. Parasit Vectors. 2018;11:606.

31. Russell TL, Beebe NW, Bugoro H, Apairamo A, Chow WK, Cooper RD, et al. Frequent blood feeding enables insecticide-treated nets to reduce transmission by mosquitoes that bite predominately outdoors. Malar J. 2016:15:156.

32. Russell TL, Beebe NW, Cooper RD, Lobo NF, Burkot TR. Successful malaria elimination strategies require interventions that target changing vector behaviours. Malar J. 2013;12:56.

33. Over M, Bakote'e B, Velayudhan R, Wilikai P, Graves PM. Impregnated nets or DDT residual spraying? Field effectiveness of malaria prevention techniques in Solomon Islands, 1993-1999. Am J Trop Med Hyg. 2004;71(Suppl 2):214-23.

34. Kere NK, Parkinson AD, Samrawickerema WA. The effect of permethrin impregnated bednets on the incidence of Plasmodium falciparum, in children of north Guadalcanal, Solomon Islands. Southeast Asian J Trop Med Public Health. 1993;24:130-7.

35. Bhatt S, Weiss DJ, Cameron E, Bisanzio D, Mappin B, Dalrymple U, et al. The effect of malaria control on Plasmodium falciparum in Africa between 2000 and 2015. Nature. 2015;526:207-11.
36. Cohen J, Smith D, Cotter C, Ward A, Yamey G, Sabot O, et al. Malaria resurgence: a systematic review and assessment of its causes. Malar J. 2012;11:122.

37. Programme NVDC. Solomon Islands Annual Malaria Program Report (2017). Honiara: Ministry of Health and Medical Services; 2017.

38. WHO. Global vector control response 2017 - 2030. Geneva: World Health Organization; 2017.

39. Pollard EJM, MacLaren D, Russell TL, Burkot TR. Protecting the peridomestic environment: the challenge for eliminating residual malaria. Sci Rep. 2020;10:7018.

40. WHO. Indoor Residual Spraying. An operational manual for indoor residual spraying (IRS) for malaria transmission control and elimination. 2nd Edn. Geneva: World Health Organization; 2015.

41. Russell TL, Farlow R, Min M, Espino E, Mnzava A, Burkot TR. Capacity of National Malaria Control Programmes to implement vector surveillance: a global analysis. Malar J. 2020;19:422.

42. Kelly G, Hii J, Batarii W, Donald W, Hale E, Nausien J, et al. Modern geographical reconnaissance of target populations in malaria elimination zones. Malar J. 2010;9:289.

\section{Publisher's Note}

Springer Nature remains neutral with regard to jurisdictional claims in published maps and institutional affiliations.
Ready to submit your research? Choose BMC and benefit from:

- fast, convenient online submission

- thorough peer review by experienced researchers in your field

- rapid publication on acceptance

- support for research data, including large and complex data types

- gold Open Access which fosters wider collaboration and increased citations

- maximum visibility for your research: over $100 \mathrm{M}$ website views per year

At BMC, research is always in progress.

Learn more biomedcentral.com/submissions 